\title{
PELATIHAN PEMBUATAN MINYAK KEMIRI BAGI KELOMPOK IBU- IBU PKK DESA BOUWELI
}

\author{
Martasiana Karbeka*, Andri P. Timung \\ Universitas Tribuana Kalabahi, Indonesia \\ *martasianakarbeka@untribkalabahi.ac.id
}

\begin{abstract}
Bouweli Village is one of the villages in Pantar District, Alor Regency. The village's most prominent potential is the result of candlenut plantations. The candlenut commodity is a mainstay of society to support the family economy. The candlenut produced is sold directly without any processing. If the candlenut production increases, the price of candlenut will decrease. Therefore, PKK mothers conducted training in making candlenut oil with the aim of improving the community's economy. With this training, mothers gain knowledge and skills that can become capital in business development. The training method applied was in the form of distributing material to participants and describing the material in detail according to the stages of the hazelnut oil-making process. Furthermore, the direct practice of making hazelnut oil was carried out. The results of the training were very satisfying because the training participants understood well the process of making hazelnut oil and the resulting clear yellow hazelnut oil. This knowledge and skills can be the initial capital in developing candlenut oil businesses by PKK women in Bouweli Village.
\end{abstract}

Keywords: training, hazelnut, making hazelnut oil

\begin{abstract}
Abstrak
Desa Bouweli merupakan salah satu desa di Kecamatan Pantar Kabupaten Alor. Potensi desa yang paling menonjol adalah hasil perkebunan kemiri. Komoditi kemiri menjadi andalan masyarakat untuk mendukung perekonomian keluarga. Kemiri yang dihasilkan langsung dijual tanpa proses pengolahan. Jika produksi kemiri meningkat maka harga kemiri akan merosot. Oleh karena itu, dilakukan pelatihan pembuatan minyak kemiri bagi ibu-ibu PKK dengan tujuan untuk dapat meningkatkan ekonomi masyarakat. Dengan pelatihan ini, ibu-ibu mendapat pengetahuan dan ketrampilan yang dapat menjadi modal dalam pengembangan usaha. Metode pelatihan yang diterapkan berupa pembagian materi kepada peserta dan pemaparan materi secara rinci sesuai dengan tahapan prose pembuatan minyak kemiri. Selanjutnya dilakukan praktek langsung pembuatan minyak kemiri. Hasil pelatihan sangat memuaskan karena peserta pelatihan memahami dengan baik prose pembuatan minyak kemiri dan minyak kemiri yang dihasilkan berwarna kuning jernih. Pengetahuan dan ketrampilan ini dapat menjadi modal awal dalam pengembangan usaha minyak kemiri oleh ibu-ibu PKK di Desa Bouweli.
\end{abstract}

Kata Kunci: Pelatihan, kemiri, pembuatan minyak kemiri

Submitted: 2020-09-09

Revised: 2020-09-22

Accepted: $2020-09-25$

\section{Pendahuluan}

Tanaman kemiri merupakan salah satu tanaman perkebunan yang dibudidayakan oleh masyarakat Kabupaten Alor. Hasil tanaman kemiri menjadi andalan untuk mendukung perekonomian masyarakat dalam memenuhi kebutuhan hidup yang membutuhkan biaya cukup besar misalnya pembangunan rumah, pendidikan, kegiatan keagamaan, kegiatan adat istiadat, perkawinan dan lainnya. Sedangkan untuk memenuhi kebutuhan sehari-hari masyarakat bergantung pada hasil pertanian (padi, jagung, ubiubian, dan hasil pertanian lainnya). Desa bouweli merupakan salah satu desa yang berada di Kecamatan Pantar. Berdasarkan data statistic 2008, Kecamatan Pantar memiliki luas 
perkebunan kemiri 926 dengan produktivitas produksi sebanyak 495 ton per tahun. Selain kemiri, terdapat tanaman perkebunan lainnya seperti jambu mete, jati, dan aren namun dengan luas area perkebunan yang lebih kecil.

Masyarakat Desa Bouweli masih memafaatkan kemiri secara terbatas pada pemakaian untuk bumbu masak, ramuan pembuatan obat atau hasil kemiri yang diperoleh langsung dijual. Produksi kemiri setiap tahun sangat tinggi namun tidak sebanding dengan harga jual dipasaran. Harga jual kemiri dipasaran tidak tetap berkisar antara (Rp 15.000 sampai Rp 25.000 per kilogram). Kandungan minyak dalam biji kemiri tergolong tinggi yaitu 55 - $66 \%$ sehingga dengan pengolahan lebih lanjut seperti pembuatan minyak kemiri akan memberikan nilai jual yang lebih tinggi. Hal ini akan berdampak pada peningkatan ekonomi masyarakat Desa Bouweli. Masyarakat Desa Bouweli pada umumnya bermata pencaharian sebagai petani $(>90 \%)$ sehingga kehidupan masyarakat sangat bergantung pada hasil pertanian dan perkebunan. Jika harga jual kemiri anjlok karena produksi yang tinggi, masyarakat akan tetap menjual hasil kemiri untuk pemenuhan kebutuhan karena tidak ada pilihan lain.

Berdasarkan hasil wawancara dengan ibu-ibu PKK Desa Bouweli, buah kemiri dimanfaatkan sebatas sebagai bumbu masak dan belum pernah mengolah biji kemiri menjadi minyak kemiri. Sebelum mengenal berbagai produk minyak rambut, mereka memanfaatkan kemiri untuk perawatan rambut dengan cara membakar biji kemiri kemudian dihaluskan lalu dioleskan di rambut. Sebelum dilaksanakan praktek pembuatan minyak kemiri, para ibu PKK diberikan pemahamanan pengembangan potensi kemiri untuk menjadi minyak kemiri. Arahan tersebut mendapat respon yang sangat baik. Ibuibu dapat dilatih ketrampilan untuk pemanfaatan hasil kemiri yang melimpah dan ini sebagai pioneer untuk membangun usaha mandiri dalam membantu ekonomi keluarga. Ibu-ibu PKK Desa Bouweli diberikan pemahaman tentang berbagai manfaat yang dapat diperoleh dari minyak kemiri diantaranya untuk mengobati pembengkakan pada sendi, menjaga kelembapan dan melindungi kulit dari sinar matahari, untuk menjaga kesehatan rambu (menghitamkan rambut dan mencegah kerontokan) serta memberi nutrisi pada kulit kepala agar rambut tumbuh dengan lebat dan subur.

Berdasarkan hasil observasi dan wawancara dengan masyarakat Desa Bouweli ditemukan beberapa permasalahan diantaranya:

1. Produksi kemiri sangat tinggi namun kurangnya pengetahuan masyarakat untuk teknik pengolahan kemiri lebih lanjut.

2. Masyarakat secara umum telah dimanja dengan sumber daya alam yang melimpah sehingga masyarakat secara umum memillih untuk menikmati hasil yang telah tersedia

3. Ibu-ibu yang umumnya ibu rumah tangga banyak memiliki waktu luang untuk dapat diberdayakan

4. Belum adanya kegiatan pendampingan masyarakat untuk mengenalkan teknik pengolahan kemiri agar bernilai ekonomi 


\section{Metode}

Mitra yang terlibat dalam kegiatan pengabdian ini umumnya ibu-ibu PKK Desa Bouweli da nada juga keterlibatan perangkat desa dan para tokoh masyarakat. Merujuk pada hasil identifikasi potensi desa dan analisis masalah dan serta situasi dan kondisi di Desa Bouweli. Oleh karena itu, metode pelaksanaan pengabdian masyarakat dilakukan dalam beberapa tahapan yakni; 1) tahapan persiapan alat dan bahan yang akan digunakan pada saat pelatihan 2) tahapan persiapan materi. Kegiatan ini diawali dengan pemberian materi dalam bentuk hardcopy kepada ibu-ibu yang sudah lansia. Untuk peserta lainnya, materi dibagikan dengan memanfaatkan social media seperti whatsapp. 3) penyampaian materi/sosialisasi yang bertujuan memberikan pemahaman tentang manfaat minyak kemiri dan menjelaskan secara terperinci tentang bagan alir pembuatan minyak kemiri. 4) tahap pelaksanaan, kegiatan ini dilaksanakan pada hari Selasa, 18 Agustus 2020 Pukul 09.00 WITA-selesai, bertempat di Kantor Desa Bouweli. Prosedur pembuatan minyak kemiri mencakup empat tahapan mencakup pembuatan serpih, perajangan dan penggilingan serta tempering atau pemasakan.

Rincian prosedur pembuatan minyak kemiri sebagai berikut:

Siapkan biji kemiri yang telah terkupas sempurna dari cangkangnya.
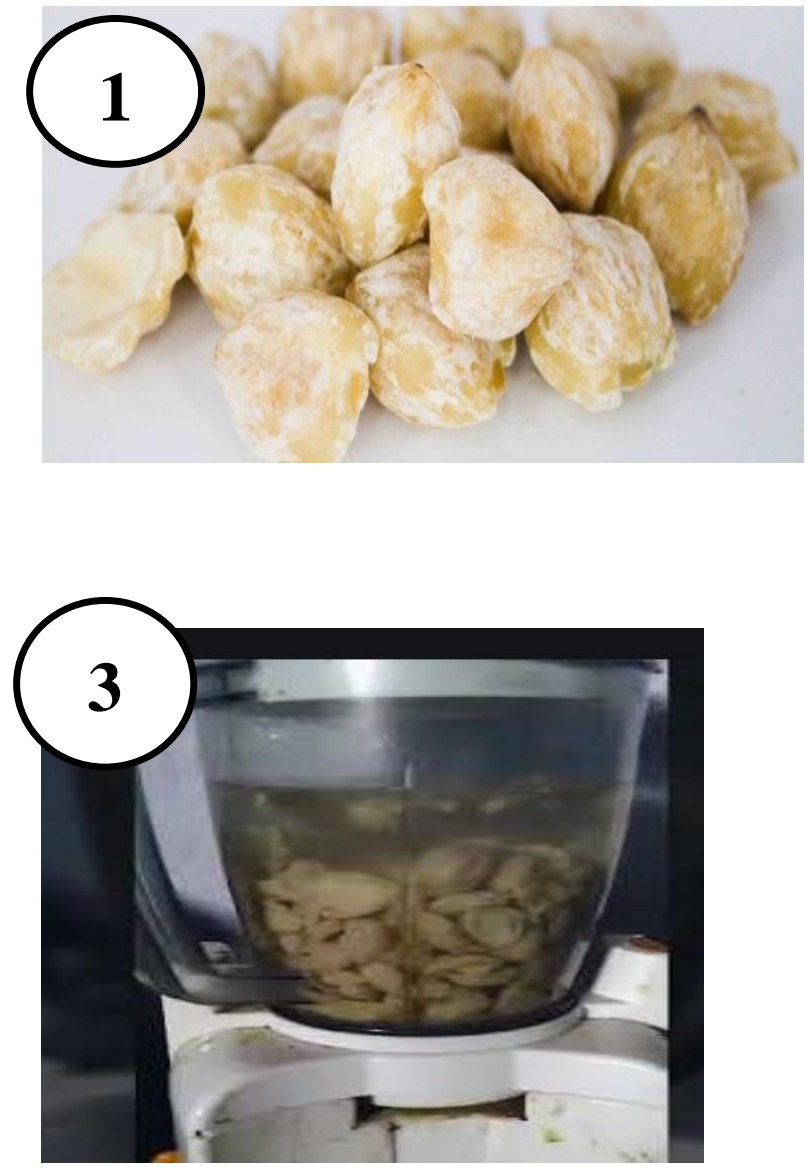

Kemiri dihaluskan dengan cara ditumbuk/digerus/diblender (perbandingan air dan kemiri 1:3)

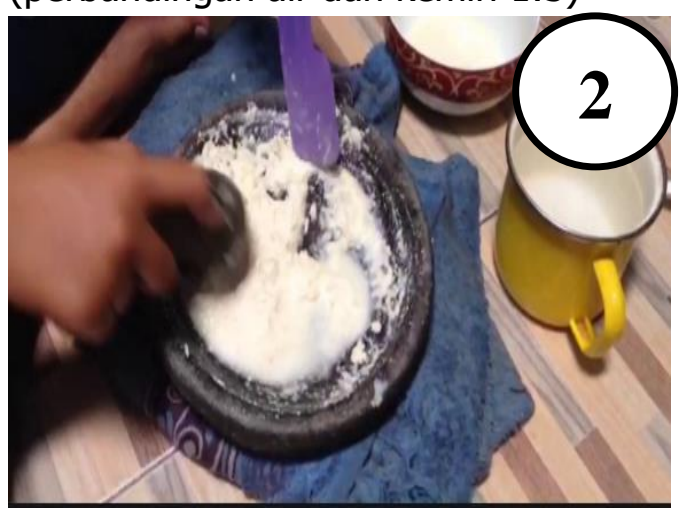

Air santan kemiri diperas lalu dimasak

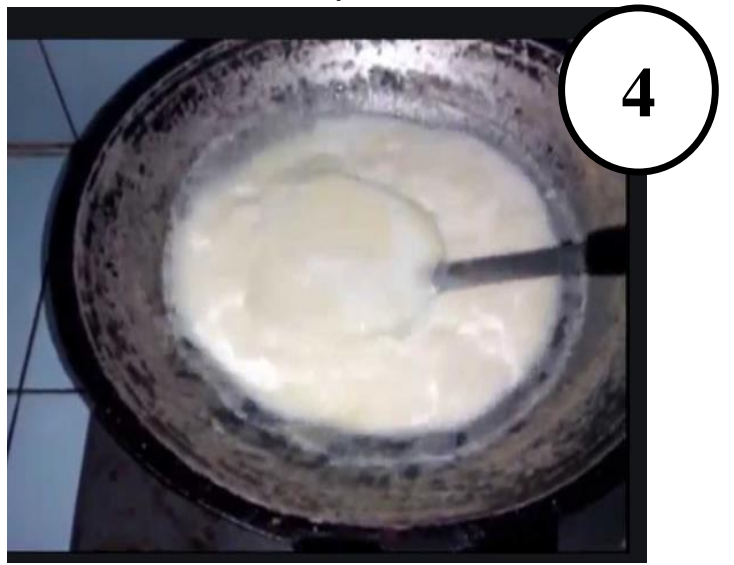




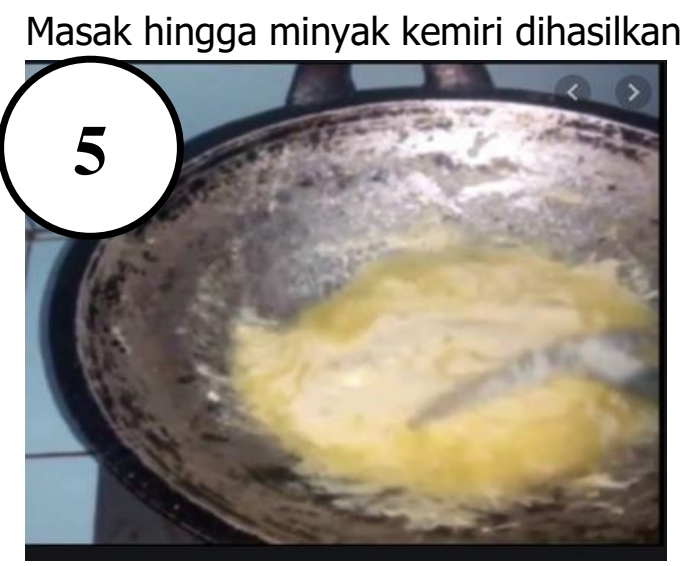

Gambar 1. Proses Pembuatan minyak kemiri

\section{Hasil dan Pembahasan}

Kegiatan pembuatan minyak kemiri dimulai dengan pengumpulan alat dan bahan yang diperlukan oleh ibu-ibu PKK Desa Bouweli. Bahan dan peralatan yang tersedia sesuai yang dibutuhkan karena telah informasikan sehari sebelum kegiatan. Kegiatan pengabdian kepada masyarakat dilaksanakan di kantor Desa Bouweli yang diawali dengan sambutan yang disampaikan oleh Kepala Desa Bouweli Bapak Robinson Waang, SH sekaligus membuka kegiatan pengabdian kepada masyarakat secara resmi.

Kegiatan selanjutnya adalah pembagian materi pembuatan minyak kemiri (hardcopy dan softcopy) kepada ibu-ibu PKK dan penjelasan materi. Materi yang dipaparkan berisikan tentang kandungan senyawa pada minyak kemiri serta manfaatnya. Ibu-ibu PKK diberikan pemahaman tentang bagaimana memanfaatkan potensi produksi kemiri yang cukup tinggi menjadi minyak kemiri yang bernilai ekonomi. Setelah sesi pemaparan materi selanjutnya dibuka sesi tanya jawab dan pertanyaan yang diberikan pada umumnya tentang cara pembuatan minyak kemiri dan bahan tambahan yang diperlukan dalam pembuatan minyak kemiri. Selanjutnya dilakukan praktek pembuatan minyak kemiri. Namun, dikarenakan kehadiran ibu-ibu PKK yang cukup banyak maka dibagi dalam dua kelompok untuk dilakukan praktek pembuatan minyak kemiri dengan cara pemanasan. Kelompok pertama menggunakan kompor minyak tanah untuk proses pemanasan dan kelompok kedua menggunakan kayu bakar.
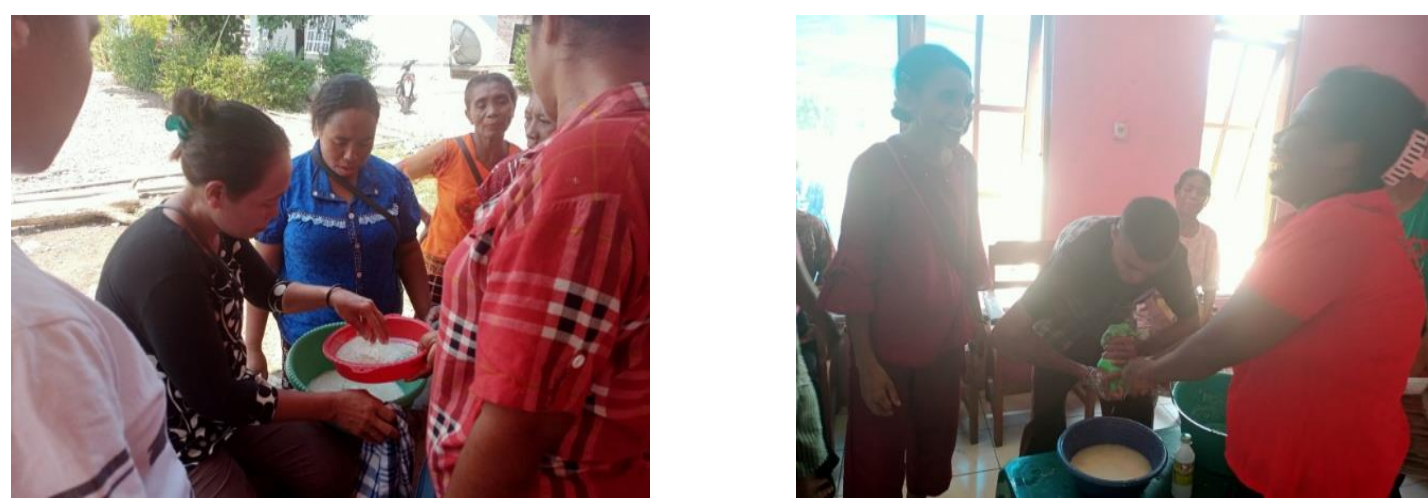

Gambar 2. Proses pengambilan santan kemiri 

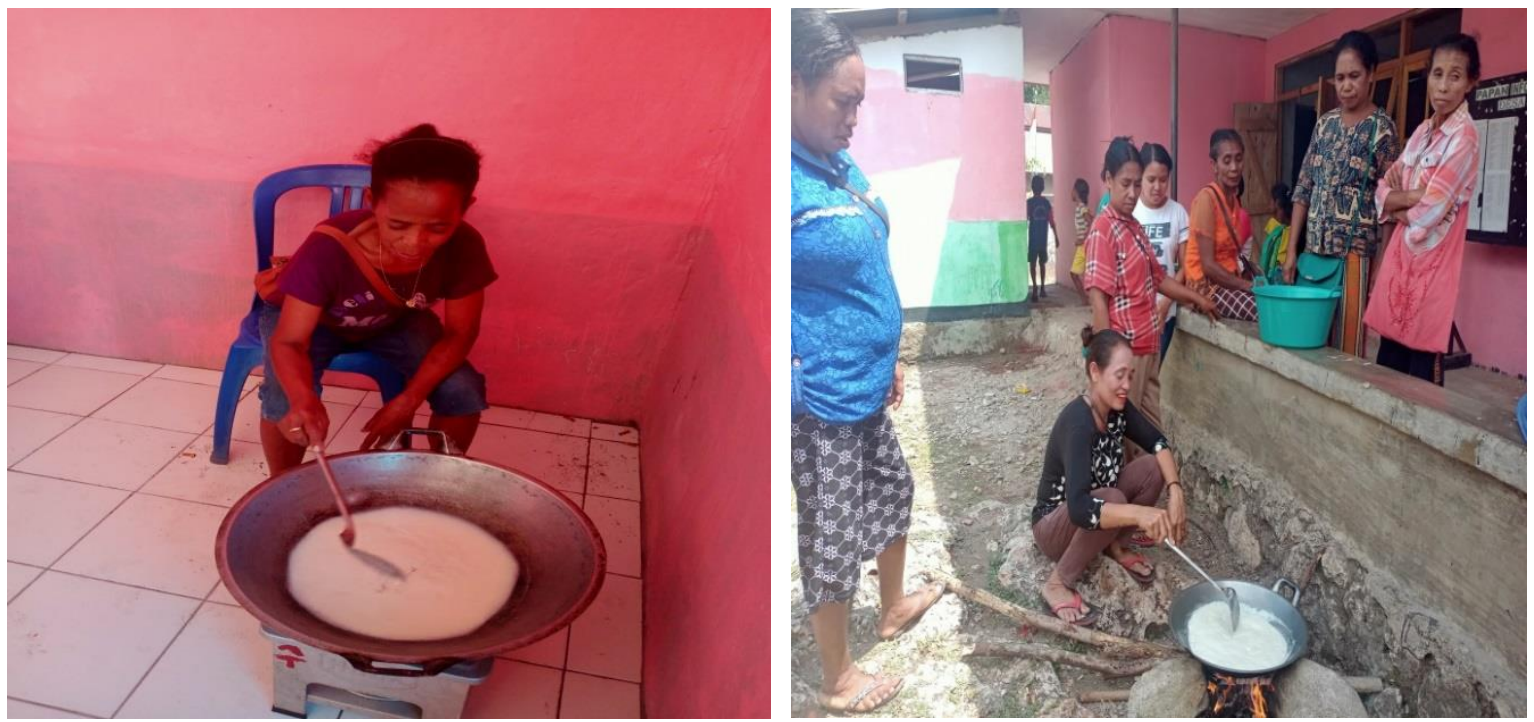

Gambar 3. Proses pemanasan
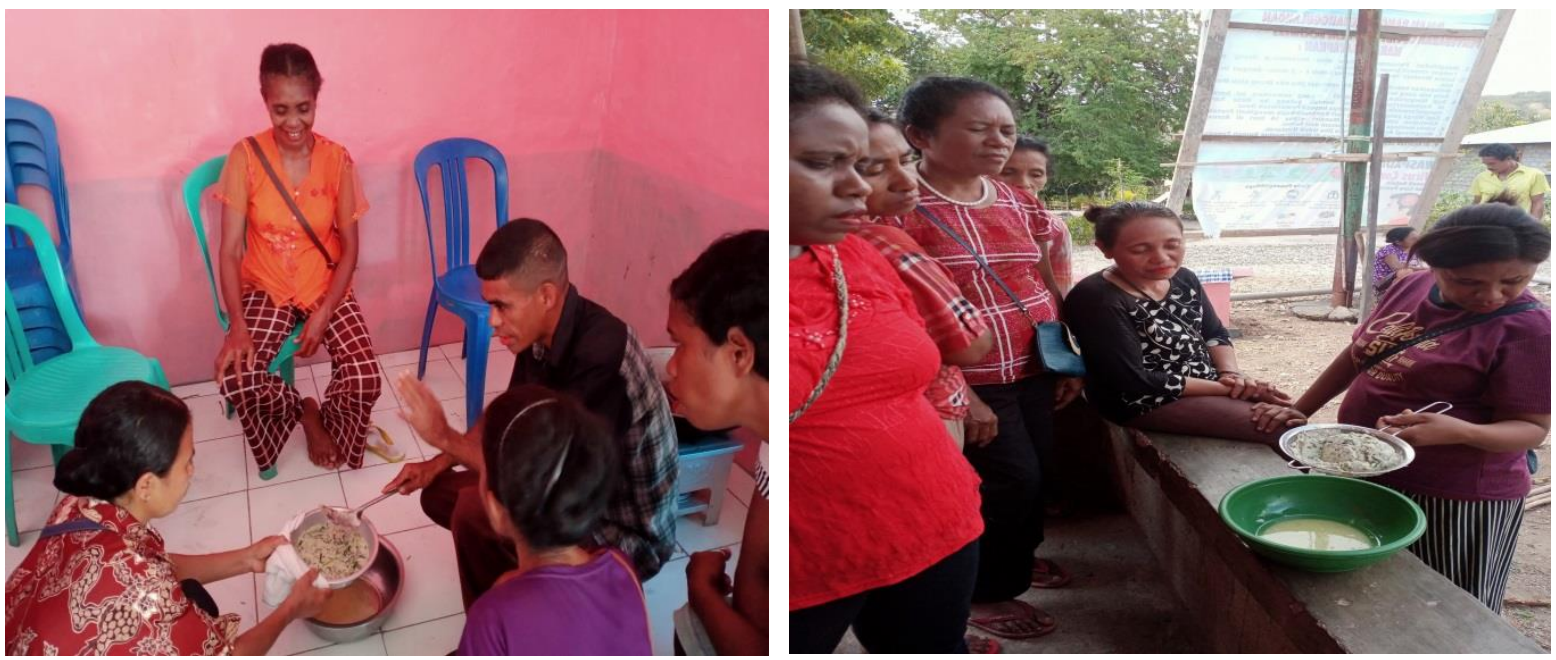

Gambar 4. Proses penyaringan minyak kemiri

Pada pelatihan pembuatan minyak kemiri digunakan cara yang paling sederhana yang mudah dilakukan oleh ibu-ibu PKK Desa Bouweli. Melalui kegiatan ini, ibu-ibu memperoleh pengetahuan yang bermanfaat untuk pengembangan produk minyak kemiri karena produktivitas kemiri yang sangat melimpah. Masyarakat sangat antusias, dilihat dari kehadiran warga yang cukup banyak dalam mengikuti pelatihan. Peserta mengikuti tahapan pelatihan dengan serius sehingga pada saat pelaksanaan dan dibagi dalam dua tim, tidak ditemui kendala yang berarti. Warga sangat aktif, terlihat dari warga yang dengan segera mencari bahan tambahan (daun waru) disekitar lokasi pelatihan untuk ditambahkan ke dalam pembuatan minyak kemiri.

Pengolahan kemiri menjadi minyak kemiri sangat efektif dan efisien dikarenakan prosesnya mudah dan sederhana serta biaya produksi yang sangat murah. Waktu pengerjaan sangat singkat dengan biaya nilai jual yang cukup menjanjikan.

Adapun evaluasi pada pelatihan ini diantaranya:

1. Kehadiran peserta cukup banyak dan sangat antusian selama kegiatan berlangsung.

2. Peserta yang hadir sangat puas dengan produk minyak kemiri yang dihasilkan 
3. Perlu dilakukan pelatihan lanjutan untuk proses pemurnian dan pengemasan minyak kemiri

\section{Kesimpulan}

Kegiatan pelatihan pembuatan minyak kemiri dapat dikatakan berhasil dilihat dari antusias para peserta selama kegiatan berlangsung. Dengan adanya pelatihan secara langsung maka para peserta menjadi lebih mudah paham dan menguasai tahapan pembuatan minyak kemiri dengan baik. Produk minyak kemiri yang dihasilkan berwarna kuning jernih sesuai dengan yang diharapkan.

\section{Daftar Pustaka}

Arlene, A., Suharto, I., dan Jessica. (2010). Pengaruh Temperatur dan Ukuran Biji terhadap Perolehan Minyak Kemiri pada Ekstraksi Biji Kemiri dengan Penekanan Mekanis. Prosiding Seminar Nasional Teknik Kimia "Kejuangan": Pengembangan Teknologi Kimia untuk Pengolahan Sumber Daya Alam Indonesia. ISSN: 16934393.

Anonim, Kecamatan Pantar Dalam Angka. (2017). Badan Pusat Statistik [BPS] Alor.

Galuh, C.R.P., dan Paramita, V. (2016). Pengaruh Temperatur, Kecepatan Putar Ulir dan Waktu Pemanasan Awal Terhadap Perolehan Minyak Kemiri dari Biji Kemiri dengan Metode Penekanan Mekanis (Screw Press). Metana 12(1): 17-25.

Lumbantoruan, D., Rohanah, A., dan Rindang, A. (2014).Uji Pengaruh Suhu Pemanasan Biji Kemiri dengan Menggunakan Oil Press Tipe Ulir terhadap Rendemen dan Mutu Minyak Yang Dihasilkan. Jurnal Rekayasa Pangan dan Pertanian 2(3): 9298.

Nababan, J., Sahrial., dan Sari, F.P. (2018). Pengaruh Suhu Pemanasan Terhadap Rendemen dan Mutu Minyak Biji Kemiri (Aleurites Moluccana) dengan Metode Maserasi Menggunakan Pelarut Heksana. Prosiding Seminar Nasional Fakultas Pertanian Universitas Jambi. Pembangunan Pertanian Berkelanjutan Berbasis Sumberdaya Lokal. ISBN: 978-602-97051-7-1

Ketaren, S. (1986). Pengantar Teknologi Minyak dan Lemak Pangan. Cetakan pertama, Penerbit Universitas Indonesia Press, Jakarta.

Parwati, L. D. dan Suparno. (2017). Pengaruh Massa Kemiri terhadap Volume dan Karakterisasi Minyak Kemiri Hasil Pengolahan Tradisional sebagai Bahan Dasar Biofuel. Jurnal Fisika 6(5): 378-384.

Rifdah. (2017). Pengaruh Operasi Temperatur Pemanasan,Waktu Pemanasan Terhadap Persen Yield pada Proses Pengurasan Minyak Biji Kemiri Mengunakan Peralatan Expeller Pressing. Distilasi 2(1): 55-64.

Standar Nasional Indonesia. (2006). Minyak Kemiri. SNI 01-4462-1998. 